\title{
Molecular signatures for obesity and associated disorders identified through partial least square regression models
}

\author{
Neeraj Sinha ${ }^{1}$, Sachin Sharma ${ }^{1 \dagger}$, Parul Tripathi ${ }^{1 \dagger}$, Simarjeet Kaur Negi ${ }^{1}$, Kamiya Tikoo ${ }^{1}$, Dhiraj Kumarr, \\ Kanury VS Rao ${ }^{1}$ and Samrat Chatterjee ${ }^{1,2^{*}}$
}

\begin{abstract}
Background: Obesity is now a worldwide epidemic disease and poses a major risk for diet related diseases like type 2 diabetes, cardiovascular disease, stroke and fatty liver among others. In the present study we employed the murine model of diet-induced obesity to determine the early, tissue-specific, gene expression signatures that characterized progression to obesity and type 2 diabetes.

Results: We used the C57BL/6 J mouse which is known as a counterpart for diet-induced human diabetes and obesity model. Our initial experiments involved two groups of mice, one on normal diet (ND) and the other on high-fat and high-sucrose (HFHSD). The later were then further separated into subgroups that either received no additional treatment, or were treated with different doses of the Ayurvedic formulation KAL-1. At different time points (week3, week6, week9, week12, week15 and week18) eight different tissues were isolated from mice being fed on different diet compositions. These tissues were used to extract gene-expression data through microarray experiment. Simultaneously, we also measured different body parameters like body weight, blood Glucose level and cytokines profile (anti-inflammatory \& pro-inflammatory) at each time point for all the groups.

Using partial least square discriminant analysis (PLS-DA) method we identified gene-expression signatures that predict physiological parameters like blood glucose levels, body weight and the balance of pro- versus anti-inflammatory cytokines. The resulting models successfully predicted diet-induced changes in body weight and blood glucose levels, although the predictive power for cytokines profiles was relatively poor. In the former two instances, however, we could exploit the models to further extract the early gene-expression signatures that accurately predict the onset of diabetes and obesity. These extracted genes allowed definition of the regulatory network involved in progression of disease.
\end{abstract}

Conclusion: We identified the early gene-expression signature for the onset of obesity and type 2 diabetes. Further analysis of this data suggests that some of these genes could be used as potential biomarkers for these two disease-states.

Keywords: Obesity, Type-II diabetes, Gene signature, Partial least square model, Biological classifications, Hub-proteins

\section{Background}

The World Health Organization (WHO) recently published that there are over 500 million adults in the whole world who were found to be clinically obese [1]. Obesity is described as an accumulation of adipose tissue and caused by a combination of environmental factors such

\footnotetext{
*Correspondence: samrat.ct@gmail.com

${ }^{\dagger}$ Equal contributors

'Immunology Group, International Centre for Genetic Engineering and Biotechnology, Aruna, Asaf Ali Marg, New Delhi 110067, India

2Present address: Drug Discovery Research Centre, Translational Health Science \& Technology Institute, Gurgaon 122016, India
}

as excessive dietary calorie intake, lack of physical activity and genetic susceptibility [2,3]. In spite obesity has been recognized as a problem for decades, it is still on the rise and gradually gaining an epidemic status swapping malnutrition and infectious diseases [2]. Moreover, obesity may cause other health problems, like development of type 2 diabetes mellitus (T2D), coronary heart disease, certain form of cancer etc. [4]. Among these health problems, T2D showed a major link with obese patients and thus undoubtedly comes up as another intriguing health problem of 21st century. T2D is a syndrome

\section{Biomed Central}


with a diverse phenotype, which is not only marked by hyperglycaemia, but also by dyslipidaemia i.e. elevated triglyceride (TG), and elevated plasma free fatty acid (FFA) levels.

Although pharmaceutical approaches to track the problem of obesity and its related disorders are being aggressively pursued, approaches evaluating treatment with alternative forms of herbal medicine are also of interest. For instance, Shao et al. [5] showed that curcumin is effective in the treatment of obesity and diabetes. More recently Tikoo et. al. [6] showed that KAL-1, a formulation derived from Ayurveda which a system of Indian Traditional Medicine, was extremely effective at suppressing the development of diet-induced obesity in the mouse model. Importantly, development of other related disorders of type 2 diabetes and systemic inflammation was also prevented.

Diet is one of the widespread environmental determinants for the onset of obesity and T2D. Thus, to study obesity and diabetes, we employed the diet-induced mouse model where mice were fed on a "high calorie diet" consisting of high-fat and high-sucrose (HFHSD). Our initial experiments involved two groups of mice, one on HFHSD and the other on normal diet (ND). HFHSD fed mice were then further separated into subgroups that either received no additional treatment, or were treated with different doses of the Ayurvedic formulation KAL-1. Experimental results, based on the physiological parameters like body weight, blood glucose levels and cytokine profiles, confirmed the earlier findings [6] that KAL-1 prevented mice from both obesity and diabetes. Thus, by comparing between the different groups, our experimental system offered an opportunity to identify disease-specific perturbations in gene expression in different tissues. Further, it was also our intent to employ this data for the subsequent extraction of gene expression signatures that specified progression towards diabetes and/or obesity.

So, a primary aim of the present study is to get a gene/ molecular signatures for obesity and diabetes by establishing a relation between the early gene expressions and late body response. These molecular signatures could be efficiently used to evaluate relevant biological formulations in a quick and very efficient rapid assay system based on gene expression profiling.

To obtain the molecular signature we developed a model using partial least square discriminant analysis (PLS-DA) method [7]. This algorithm is useful when multi-collinearity exists among explanatory variables and when the number of explanatory variables is very large compared to the number of observations. PLS-DA analysis reduces the multiple dimensions of data set to a principal component space and regress independent and dependent principal components. In our case, we used this algorithm model to find the relationship between the early gene-expression values (independent variable) and late physiological responses like body weight, blood glucose levels or cytokine profiles (dependent variable). We succeeded in identifying a set of genes whose early expression pattern correlated with the subsequent development of obesity and diabetes. A subsequent interrogation of the resulting tissue-specific gene expression signatures then helped to distinguish those genes, or groups of genes (modules), that may play a significant role in driving disease progression.

\section{Methods}

\section{Animal experiment}

All animal experiments were performed at BIONEEDS (Laboratory animals \& Preclinical services) Bangalore, India, and approved by institutional animal ethics committee (IAEC). BIONEEDS is approved by committee for the purpose of control and supervision of experiments on animals (CPCSEA), Ministry of forests and environments, Government of India. In the present study, we used the C57BL/6 J mouse which is known as a counterpart for diet-induced human diabetes and obesity model since this strain accumulates adipose tissue mass, insulin resistance, hyper-insulinemia, and hyper-lipidemia which is very similar to humans fed on an HFHSD [8-10]. The mice were kept at 12:12 hr light: dark photoperiod with ad libitum access to food and water. Weaned mice at the age of 3-4 weeks were divided randomly into five groups- (each group contains 30 animals): first group was fed on ND with $10 \%$ of calories coming from fat, the second group was HFHSD fed group with increased sucrose and $60 \%$ of calories coming from fat (Research diets Inc.USA), and the third, fourth and fifth group of mice were fed on HFHSD with different doses of an ethano-botanical formulation, KAL-1 and we named them as KAL-5 (5 $\mu \mathrm{g}$ of KAL-1+ HFHSD), KAL-20 $(20 \mu \mathrm{g}$ of KAL-1+ HFHSD) and KAL-75 (75 $\mu \mathrm{g}$ of KAL-1+ HFHSD). The daily weight of this aqueous formulation was $700 \mathrm{mg} / \mathrm{ml}$. A schematic diagram showing the preparation of KAL-1 is given in Figure 1(a).

We generated vast data sets for gene-expression across different tissues from mice being fed on different diet compositions. Tissues were selected on the basis of their anticipated role in obesity, diabetes, or inflammation. The selected tissues were liver, skeletal muscle, brown adipose tissue (BA), white adipose tissue from the epididymal (EA) and subcutaneous (SA) regions, and purified infiltrating macrophages (SVCs) from each of these adipose tissue sites [11-13].

The mice were periodically monitored over an eighteen week period. At the interval of every 3 weeks, five animals from each group were sacrificed and different tissues were extracted and frozen in liquid nitrogen prior to RNA extraction. The SVC macrophages and adipocytes tissues 


\section{a}

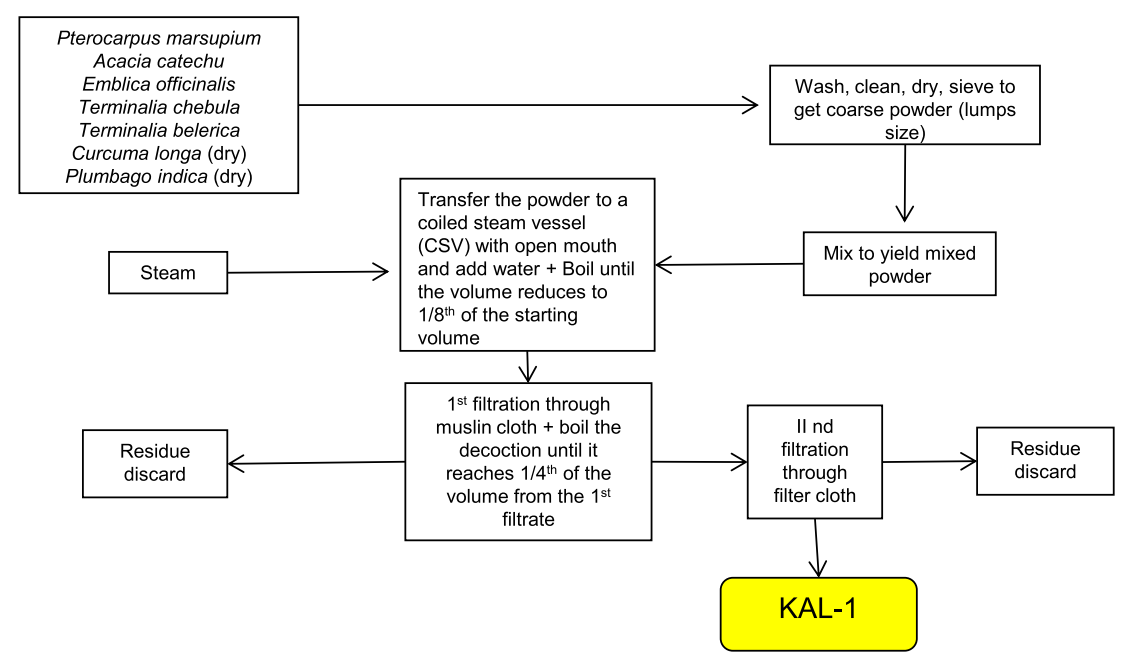

b

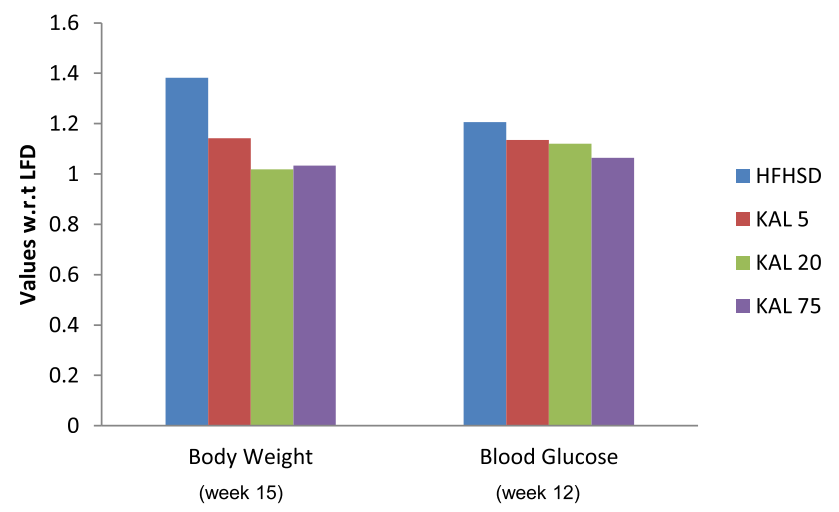

C

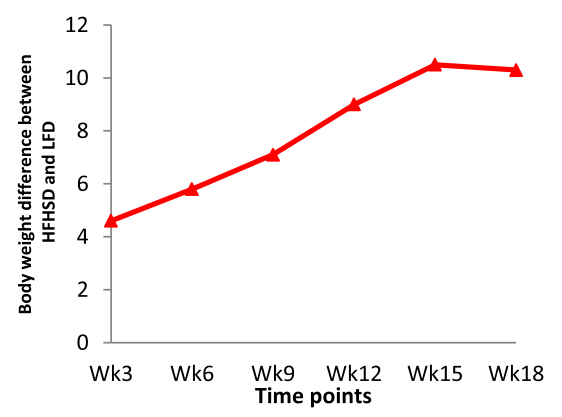

d

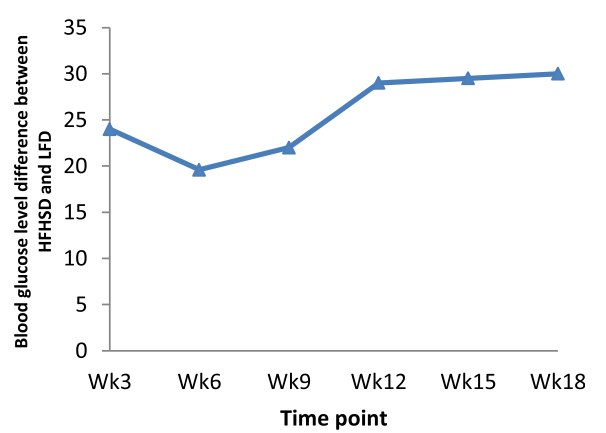

Figure 1 KAL-1 formulation and its effect on body weight and blood glucose. (a) Procedure for preparation of KAL-1 kwath. Flow chart showing the step-wise preparation of Ayurvedic formulation termed as KAL-1 [6]. This formulation was given to the mice at different concentration $(5 \mu l, 20 \mu l$ and $75 \mu l)$ along with HFHSD. (b)- (d) Body weight and Blood glucose results. (b) The difference between the body weights of the HFHSD mice and ND mice is given for each time point. (c) The difference between the blood glucose levels of the HFHSD mice and ND mice is given for each time point. (d) The average body weight of different group of mice at week 15 and blood glucose of different group of mice at week 12 with respect to the body parameter of ND mice is given.

were further processed separately using standard protocolsin brief, adipose tissue (BA, EA and SA regions) were isolated, weighed and collagenase solution was added in the concentration of $3 \mathrm{ml} / \mathrm{g}$ of the tissue. Further, tissues were homogenized and the tissue solution was kept in shaking water bath at $37^{\circ} \mathrm{C}$ for 45 minutes. After centrifugation at $3600 \mathrm{rpm}$ for 26 minutes, the pellet was treated with erythrocyte lysis buffer and adipocytes layer was saved for 
Table 1 Table summarizing tissue-wise model result for different body parameters

\begin{tabular}{|c|c|c|c|c|}
\hline Tissues & Body weight model & Blood glucose model & Anti cytokine model & Pro cytokine model \\
\hline Adipose BA & Model worked & Model worked & Model not worked & Model worked \\
\hline Adipose EA & Model not worked & Model not worked & Model worked & Model worked \\
\hline Adipose SA & Model worked & Model worked & Model worked & Model worked \\
\hline SVC BA & Model worked & Model worked & Model not worked & Model worked \\
\hline SVC EA & Model not worked & Model worked & Model worked & Model worked \\
\hline SVC SA & Model not worked & Model not worked & Model not worked & Model not worked \\
\hline Skeletal & Model worked & Model worked & Model worked & Model worked \\
\hline Liver & Model not worked & Model not worked & Model worked & Model worked \\
\hline
\end{tabular}

further processing. The treated pellet was centrifuged at $3500 \mathrm{rpm} / 10 \mathrm{~min}$ and the resulting pellet was dissolved in $1 \mathrm{x}$ PBS, further, biotin binder beads were added and solution was collected as SVC macrophages. The adipocytes layer obtained was further processed with collagenase and incubated at $37^{\circ} \mathrm{C}$ for 30 minutes in shaking water bath. After centrifugation at $3600 \mathrm{rpm}$ for $20 \mathrm{~min}$ pellet was obtained and was kept as adipocytes. The SVC macrophages and adipocytes for all the three tissues were frozen and sent for RNA extraction.

Isolated tissues were then used to extract gene-expression data for different time points (week3, week6, week9, week12, week15 and week18) for all tissues through microarray experiment. Simultaneously, we also measured different body parameters like body weight, blood Glucose level and cytokines profile (anti-inflammatory \& pro-inflammatory) at each time point for all the groups, see Figure 1(b).

\section{Normalization and noise filtration in micro-array data}

The gene-expression data were normalized according to Agilent protocols. Probe level data were summarized into a single expression value for each gene on each array using GCRMA in GeneSpring GX 11 (Agilent Technologies, http://www.chem.agilent.com/). GeneSpring (http://genespring-support.com/files/gs_12_ 6/GeneSpring-manual.pdf, page 919 and page 920) take care for probable batch effect. Array normalization involved non-linear background reduction, quantile normalization, and summarization by median polishing [14]. Moreover, for each time point we normalize the test data with the control data (ND) to take care of week-wise variation.

In the normalized data we have probe name with Gene Bank accession, gene symbol, name and description. Further for each probe we have three replicate samples and their respective geometric mean with p-value. The gene expressions in the list were given in $\log _{2}$-scale ratio between different groups with ND group. A gene is said to be significantly regulated if its expression value is greater than 1 (up-regulation) or less than -1 (down-regulation) i.e., two folds up or down with respect to the control. If the expression value lies between -1 and 1 , then the gene is said to be insignificantly perturbed. To remove noise from the data and to maintain consistency we selected only those genes which showed same kind of regulation throughout all the three replicates. Further, in this filtered gene list, we observed that there are some genes present in more than one probe and have different expression values. Therefore, as a final step of gene selection, we select those genes from the duplicate probes that have geometric mean with minimum p-value (2tailed T-test). This non-redundant (and noise free) set of genes obtained for each time point (i.e., week3, week6, week9, week12, week15 and week18) is called the master list (see Additional file 1 where the master list for week 3 and week 6 is given for Skeletal and Adipose SA for HFHSD, KAL-5, KAL-20 and KAL-75).

\section{Model formulation}

We followed modelling approach that is based on a multivariate statistical method called Partial least square discriminant analysis (PLS-DA) [7]. We used SIMCA P + from Umetrics to do this analysis [15]. The main goal of the PLS-DA model is to predict a set of dependent variable $(Y)$ from a set of independent variables $(X)$. For the PLS-DA model we first defined an independent and a dependent set of variables.

When the models were run, each of them produced a particular $\mathbf{R} 2$ and Q2 value. R2 is the percent of variation of the training set $-X$ with PCA and $Y$ with PLS - explained by the model. $\mathbf{R} 2$ is a measure of fit, i.e. how well the model fits the data [15]. A large R2 (close to 1) is a necessary condition for a good model. Q2 is the percent of variation of the training set $-X$ with PCA and $Y$ with PLS - predicted by the model according to cross validation. Q2 indicates how well the model predicts new data. A large Q2 (Q2 > $0.5)$ indicates good predictivity. Poor $\mathbf{Q} 2$ values were generally obtained either when the data are noisy, or if the relationship $X \rightarrow Y$ is poor, or when the model is dominated by a few scattered outliers. In the trained model, the independent variables are ranked depending on a score called variable importance in projection (VIP). The scores are obtained 


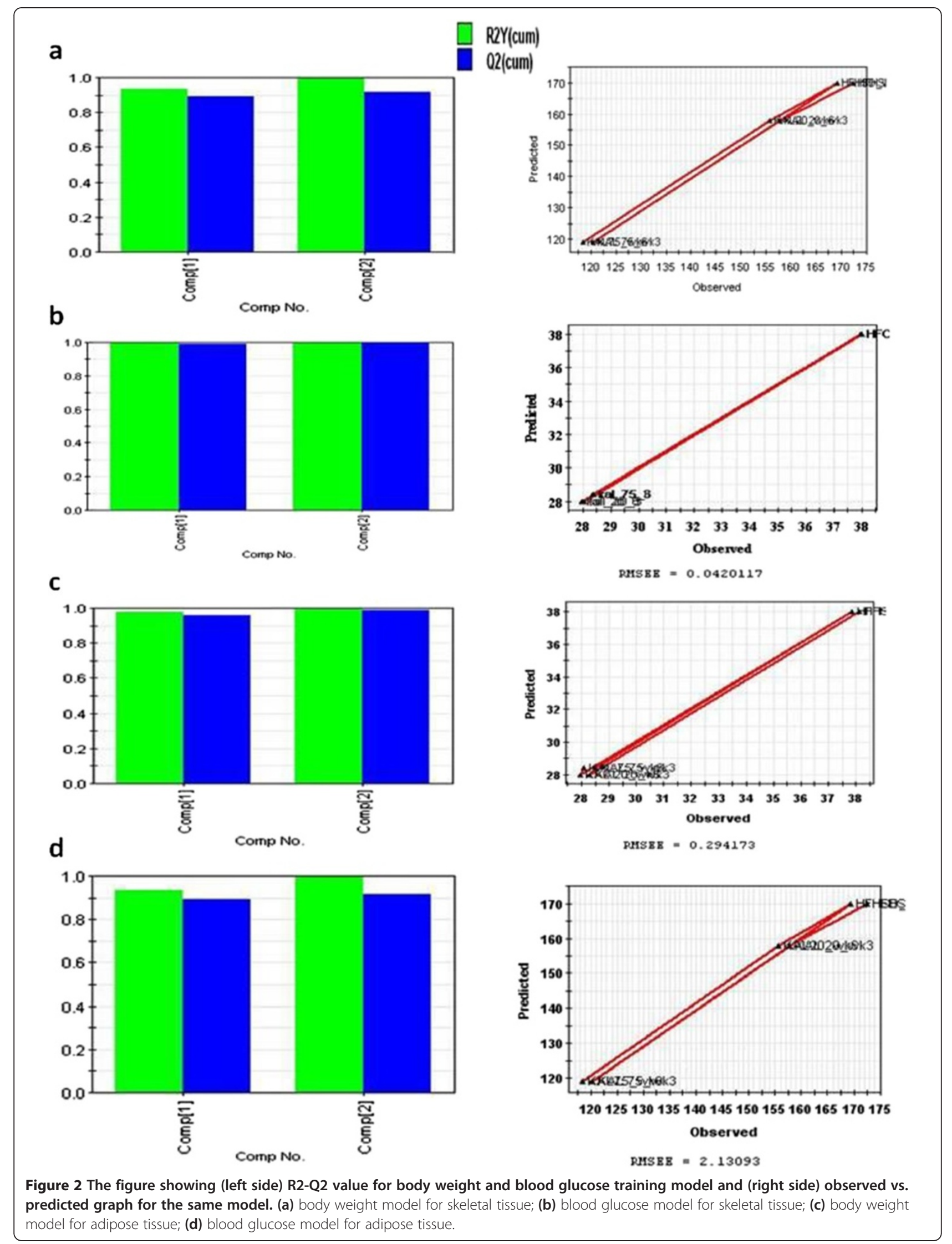




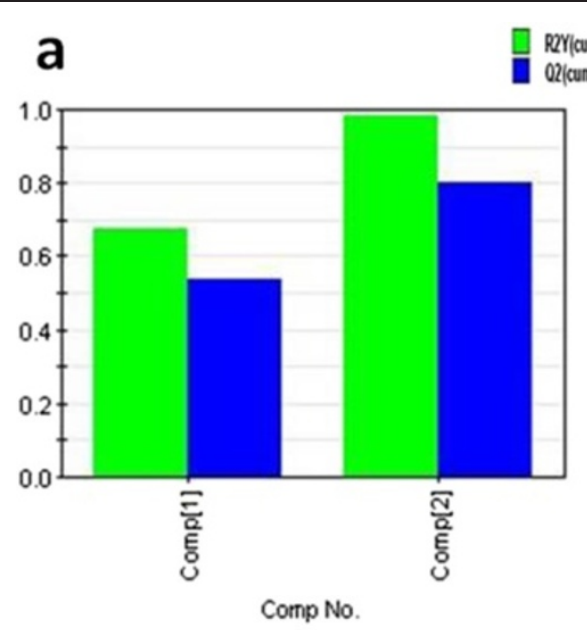

\section{b}

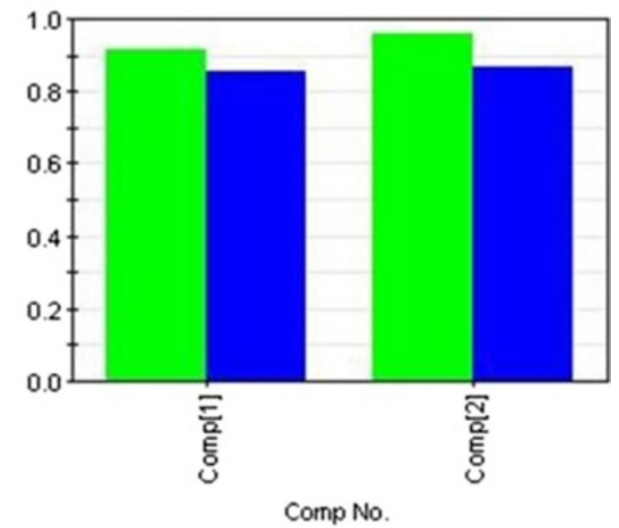

C
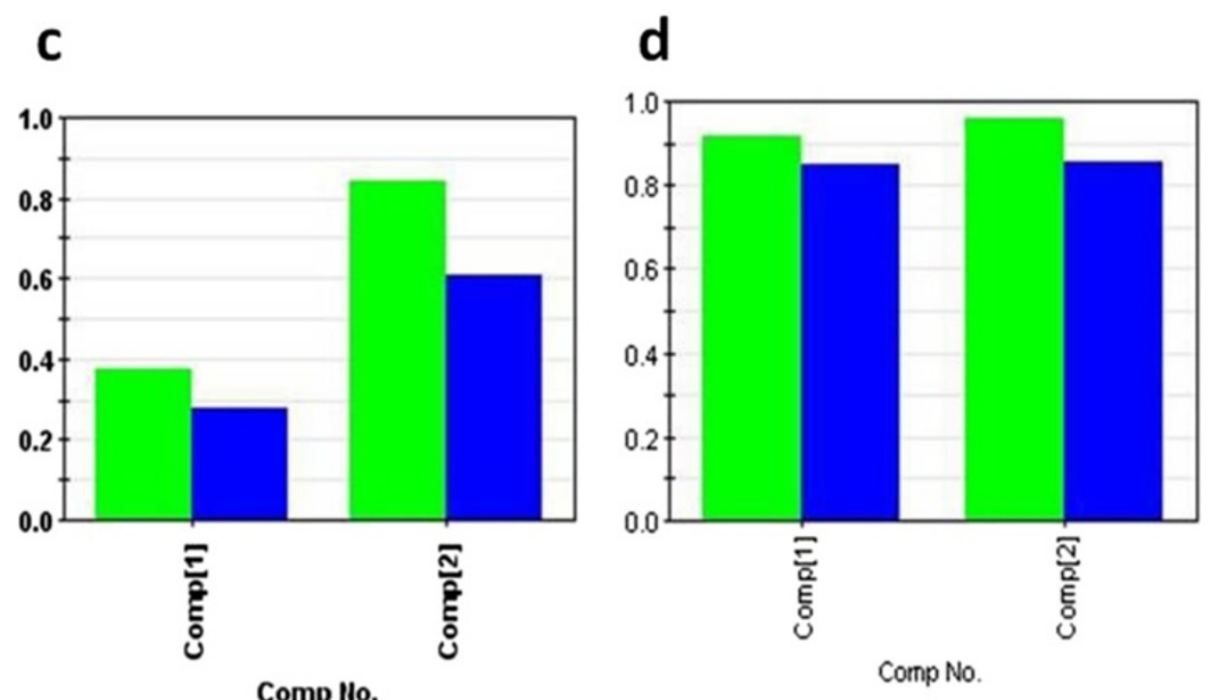

Figure 3 The figure showing R2-Q2 value for cytokines (anti-inflammatory and pro-inflammatory) training model. (a) anti-inflammatory cytokine model for skeletal tissue; (b) pro-inflammatory cytokine model for skeletal tissue; (c) anti-inflammatory cytokine model for adipose SA tissue; (d) pro-inflammatory cytokine model for adipose tissue.

from the graph of observed versus predicted value and was a measure for the predictive ability of the variable with respect to a particular parameter (for details see Additional file 2). Using a cut off value for the VIP score (Additional file 2) we select the top ranked variables and then again built our model with those selected variables.

\section{Results}

\section{Extraction of the molecular signature for obesity and diabetes}

In PLS-DA model, we took gene-expression values as the set of independent variables and dependent variable were the physiological parameters like body weight for the first model, blood glucose levels for the second model, and proand anti-inflammatory cytokine profiles for the third and fourth model respectively. The selected pro-inflammatory cytokines were GM-CSF, IFN $\gamma$, IL-1a, IL-1b, IL-6, MCP1, TNF- $\alpha$ and IL-12p70 and the anti-inflammatory cytokines were IL-4, IL-10 and IL-13.

In training the model, instead of one week, we considered gene expression values from two different weeks. This increased the range for independent variable. As a result of this increased variability our model could capture wider range of unknown data set for prediction and thus would decrease its chances for failure. We trained all our models with early time point gene-expression values as the independent variable. We chose gene-expression values from week 3 and week 6 (we selected genes common to both the weeks from the master list). In tissues, where this protocol did not work (i.e., where the model training failed), we combined those two weeks (week 3 and week 9) and took the expression profile of the union list as the independent variable. The disadvantage with the latter protocol was that 
Table 2 Model summarizations for both skeletal and adipose SA tissue

\begin{tabular}{|c|c|c|c|c|c|}
\hline Tissue name & Model (body parameter) & No. of genes & Groups used & $\begin{array}{l}\text { Input week } \\
\text { (gene expressions) }\end{array}$ & $\begin{array}{l}\text { Output week } \\
\text { (physiological result) }\end{array}$ \\
\hline \multirow[t]{4}{*}{ Skeletal } & Body weight & 150 & HFHSD, KAL-20, KAL-75 & Week 3 and week 6 & Week 15 \\
\hline & Blood glucose & 168 & HFHSD, KAL-20, KAL-75 & Week 3 and week 6 & Week 12 \\
\hline & Pro-inflammatory cytokines & 160 & HFHSD, KAL-20, KAL-75 & Week 3 and week 6 & Week 9 and week 12 \\
\hline & Anti-inflammatory cytokines & 182 & HFHSD, KAL-20, KAL-75 & Week 3 and week 6 & Week 9 and week 12 \\
\hline \multirow[t]{4}{*}{ Adipose SA } & Body weight & 147 & HFHSD, KAL-20, KAL-75 & Week 3 or week 6 & Week 15 \\
\hline & Blood glucose & 133 & HFHSD, KAL-20, KAL-75 & Week 3 or week 6 & Week 12 \\
\hline & Pro-inflammatory cytokines & 144 & HFHSD, KAL-20, KAL-75 & Week 3 or week 6 & Week 9 and week 12 \\
\hline & Anti-inflammatory cytokines & 186 & HFHSD, KAL-20, KAL-75 & Week 3 or week 6 & Week 9 and week 12 \\
\hline
\end{tabular}

there were some genes present only in one week (in the master list) and so their expression for the other week was kept blank in the model, which made the model weak. Nevertheless, we generated a model with the union list that runs when the intersection protocol fails.
For the dependent variable, as mentioned earlier, we chose different body parameter. The selections of the critical weeks for each body parameter used in different models were decided from the experimental data. The critical week is the time point where the respective body

Table 3 Test results for KAL-5 and comparison of results with the actual experimental results to check the precision of the model in terms of prediction

\begin{tabular}{|c|c|c|c|c|c|}
\hline Body response parameter & Input time (gene expression) & Output time (body parameter) & & Observed & Predicted \\
\hline \multirow[t]{16}{*}{ Pro- inflammatory cytokine } & Week 3 & Week 9 & GMCSF & 55 & 56.1 \\
\hline & & & $\mathrm{IFN \gamma}$ & 71 & 76.7 \\
\hline & & & IL1a & 103 & 98.1 \\
\hline & & & $\mathrm{IL} 1 \mathrm{~b}$ & 54 & 87.1 \\
\hline & & & IL6 & 62 & 102.6 \\
\hline & & & MCP1 & 92 & 85 \\
\hline & & & TNFa & 92 & 101.8 \\
\hline & & & IL $12 \mathrm{P} 70$ & 89 & 102.5 \\
\hline & Week 6 & Week 12 & GMCSF & 60 & 67.3 \\
\hline & & & IFNY & 99 & 89.7 \\
\hline & & & ILla & 92 & 128.4 \\
\hline & & & IL $1 \mathrm{~b}$ & 84 & 117.9 \\
\hline & & & IL6 & 97 & 129 \\
\hline & & & MCP1 & 97 & 95 \\
\hline & & & TNFa & 93 & 155 \\
\hline & & & IL12P70 & 77 & 124.7 \\
\hline \multirow[t]{6}{*}{ Anti- inflammatory cytokine } & Week 3 & Week 9 & IL4 & 41 & 52.2 \\
\hline & & & IL 10 & 63 & 68.3 \\
\hline & & & IL13 & 66 & 71.3 \\
\hline & Week 6 & Week 12 & IL4 & 55 & 54 \\
\hline & & & IL 10 & 78 & 67.5 \\
\hline & & & IL13 & 87 & 66.4 \\
\hline \multirow[t]{2}{*}{ Body weight } & Week 3 & Week 15 & - & 31.4 & 30.6 \\
\hline & Week 6 & Week 15 & & 31.4 & 32.12 \\
\hline \multirow[t]{2}{*}{ Blood glucose } & Week 3 & Week 12 & - & 160 & 158.05 \\
\hline & Week 6 & Week 12 & & 160 & 158.24 \\
\hline
\end{tabular}


Table 4 Body weight (in grams) and blood glucose level (in mg/dl) of mice exposed with KAL-A, KAL-B and KAL-C formulations

\begin{tabular}{llllll}
\hline Formulation & $\begin{array}{l}\text { Predicted body } \\
\text { weight of the } \\
\text { mice }\end{array}$ & $\begin{array}{l}\text { Effectiveness } \\
\text { (Predicted) }\end{array}$ & $\begin{array}{l}\text { Experimentally } \\
\text { observed body weight } \\
\text { of the mice }\end{array}$ & $\begin{array}{l}\text { Experimentally observed body weight of the mice } \\
\text { (converted in the range to match the reference } \\
\text { body weight range) }\end{array}$ & $\begin{array}{l}\text { Effectiveness } \\
\text { (Actual) }\end{array}$ \\
\hline KAL A & 30.89 & $+/-$ & 28.5 & 29.2 \\
KAL B & 32.02 & - & 30.8 & 37.3 \\
KAL C & 29.72 & + & 29 & 31 & + \\
\hline Formulation & $\begin{array}{l}\text { Predicted blood } \\
\text { glucose level of } \\
\text { the mice }\end{array}$ & $\begin{array}{l}\text { Effectiveness } \\
\text { (Predicted) }\end{array}$ & $\begin{array}{l}\text { Experimentally } \\
\text { observed blood } \\
\text { glucose level of the } \\
\text { mice }\end{array}$ & $\begin{array}{l}\text { Experimentally observed blood glucose level of } \\
\text { the mice (converted in the range to match the } \\
\text { reference body weight range) }\end{array}$ & $\begin{array}{l}\text { Effectiveness } \\
\text { (Actual) }\end{array}$ \\
& & & 165 & 180.15 \\
\hline KAL A & 166.33 & - & 165 & 180.15 \\
KAL B & 166.17 & - & 161 & 174.35 \\
KAL C & 164 & - & -
\end{tabular}

Second column has predicted values form the model and the fourth column is the observed values of the model. ' + ' means the formulation works and '-' means it does not work and ' $+/-^{\prime}$ means may or may not work.

parameter reaches stability i.e., beyond this critical time point the difference between the body parameter of the HFHSD mice and ND mice becomes constant. The critical week for body weight was found to be week 15 and that for blood glucose was week 12 (see Figure 1(c)-(d)). For the cytokines (anti and pro-inflammatory) we observed the critical week to be week 9 (data not shown). However, we were unable to develop a good model using data only from week 9 . Therefore, the results of week 9 and week 12 were combined and this approach worked well for both anti- and pro-inflammatory cytokines. Thus for the first model we chose the body weight of week 15 as the dependent variable. For second model, we used blood glucose levels (week 12). For third model we used antiinflammatory cytokines (week 9 and week 12) and for the fourth model we used pro-inflammatory cytokines (week 9 and week 12).
The model was constructed for each tissue and the results are summarized in Table 1 . It was observed that models satisfactorily worked only for the SA white adipose tissue and skeletal muscle. The R2-Q2 value for Skeletal and adipose tissue is given in Figures 2 and 3. Therefore, we focused on these two tissues and generated eight models (four models for each tissues corresponding to four physiological parameters), the models are given in details in Additional file 3. The models consist of finite number of genes, selected based on the VIP cutoff (see Table 2). Among these two tissues, skeletal muscle yielded better results as it worked for the set of genes that were commonly perturbed at both week 3 and week 6. For the adipose tissue on the other hand, we had to use a combined list of genes from both time points (union set) as a result of which the independent variable data set also included genes that were perturbed

Table 5 Body weights (in grams) of mice fed with 10 unknown formulations

\begin{tabular}{|c|c|c|c|c|c|}
\hline Formulation & $\begin{array}{l}\text { Predicted body } \\
\text { weight of the } \\
\text { mice }\end{array}$ & $\begin{array}{l}\text { Effectiveness } \\
\text { (predicted) }\end{array}$ & $\begin{array}{l}\text { Experimentally } \\
\text { observed body } \\
\text { weight of the mice }\end{array}$ & $\begin{array}{l}\text { Experimentally observed body weight of the mice } \\
\text { (converted in the range to match the reference } \\
\text { body weight range) }\end{array}$ & $\begin{array}{l}\text { Effectiveness } \\
\text { (Actual) }\end{array}$ \\
\hline $\mathrm{NF}_{-} 1$ & 31.76 & $+/-$ & 36.7 & 32.24 & $+/-$ \\
\hline NF_2 & 32.89 & - & 38.88333 & 34.64 & - \\
\hline NF_3 & 33.1 & - & 37.63333 & 33.264 & - \\
\hline NF_4 & 31.75 & $+/-$ & 39.3 & 35.0927 & - \\
\hline NF_5 & 31.48 & $+/-$ & 41.43333 & 37.43 & - \\
\hline NF_6 & 31.21 & $+/-$ & 41 & 36.96 & - \\
\hline NF_7 & 31.94 & $+/-$ & 39.98333 & 35.84 & - \\
\hline NF_8 & 31.07 & $+/-$ & 36.95 & 32.51 & $+/-$ \\
\hline NF_9 & 30.57 & $+/-$ & 36.68333 & 32.22 & $+/-$ \\
\hline NF_10 & 31.24 & $+/-$ & 34.86667 & 30.22 & $+/-$ \\
\hline
\end{tabular}

Second column has predicted values form the model and the fourth column is the observed values of the model. ' + ' means the formulation works and '-' means it does not work and ' $+/{ }^{\prime}$ ' means may or may not work. 
Table 6 Blood glucose level (in $\mathrm{mg} / \mathrm{dl}$ ) of mice fed with 10 unknown formulations

\begin{tabular}{llllll}
\hline Formulation & $\begin{array}{l}\text { Predicted blood } \\
\text { glucose level from } \\
\text { the model }\end{array}$ & $\begin{array}{l}\text { Effectiveness } \\
\text { (Predicted) }\end{array}$ & $\begin{array}{l}\text { Experimentally } \\
\text { observed blood } \\
\text { glucose level }\end{array}$ & $\begin{array}{l}\text { Experimentally observed blood glucose level of the } \\
\text { mice (converted in the range to match the } \\
\text { reference body weight range) }\end{array}$ & $\begin{array}{l}\text { Effectiveness } \\
\text { (Actual) }\end{array}$ \\
\hline NF_1 & 150.087 & +- & 153.8333 & 155.068 \\
NF_2 & 155.671 & - & 168 & 169.48 \\
NF_3 & 161.86 & - & 159.5 & 160.83 \\
NF_4 & 151.751 & $+/-$ & 152.6667 & 153.88 \\
NF_5 & 160.533 & - & 167.3333 & 168.8 \\
NF_6 & 160.029 & - & 175.3333 & 176.93 \\
NF_7 & 158.374 & - & 166.6667 & 168.12 \\
NF_8 & 160.225 & - & 155.8333 & 157.1 \\
NF_9 & 166.757 & - & 153.1667 & 154.4 \\
NF_10 & 154.106 & $+/-$ & 150.1667 & 151.34 \\
\hline
\end{tabular}

Second column has predicted values form the model and the fourth column is the observed values of the model. ' + ' means the formulation works and '-' means it does not work and ' $+/{ }^{\prime}$ ' means may or may not work.

at only one of the two time points and the obtained model yield weak predictions. Consequently, we focused only on the skeletal muscle as the most appropriate tissue for deriving the predictive models of interest.

For model training, we used experimental data consisted of groups from ND, HFHSD, KAL-20 and KAL-75. Thus for model testing we could use unknown data of KAL-5 group. The gene-expressions of KAL-5 for week 3 and 6 were used to predict the body weight for week 15 , blood glucose level of week 12 and cytokines (anti-inflammatory \& pro-inflammatory) for week 9 and week 12. In the new model, we put the gene-expression of the selected genes under their respective gene names in the $X$ matrix (for the independent set) and kept the parameter corresponding to that row empty in the $Y$ matrix (for the dependent set). If any gene is not present in the new set due to noise filtration, we kept the spot empty in the $X$ matrix. Once the model is run we obtained the $\mathbf{R} \mathbf{2}$ and $\mathbf{Q} 2$ values explaining the goodness and predictive ability of our model. We compared the predicted values with the experimental value and the results are given in Table 3. It was observed that body weight and blood glucose level were better models in terms of consistency and thus can be used to test biological formulations against obesity and diabetes.

\section{Deriving mathematical scheme for evaluating biological formulation for obesity and diabetes}

The model is ready to predict late time point body parameters, like body weight and blood glucose level, from early gene expression values obtained from new experiments. We could check the predictive ability of the models by comparing the predicted values with the experimentally obtained results. For comparison, the unknown experimental data need to be normalized with the reference data (the data used to build the model). For this normalization, we took the body parameters of the ND and HFHSD mice as the minimum and maximum values of the experimental range and converted them to the range of the reference experiment. Since this is a linear shift in scale and range, we used the Celsius-Fahrenheit conversion concept. Let the body weight of the ND mice of the reference experiment be $x_{1}$ gram and HFHSD mice be $x_{2}$ gram. Let the body weight of the ND mice of the new experiment be $y_{1}$ gram and HFHSD be $y_{2}$ gram. Since there is a linear relation between the ND of the model reference with the new experiment $\left(x_{1}, y_{1}\right)$, and HFHSD of the model reference with the new experiment $\left(x_{2}, y_{2}\right)$, so these two points will pass through a line. Let the equation of the line be $y=m x+c$, where $m$ is the slope of the line and $c$ is the intercept of the line. To get the equation we need to find the unknown parameter $m$ and $c$. For this we substituted $(x, y)$ from the equation of the line with $\left(x_{1}, y_{1}\right)$ and $\left(x_{2}, y_{2}\right)$ and got

$$
\begin{aligned}
& y_{1}=m x_{1}+c \\
& y_{2}=m x_{2}+c
\end{aligned}
$$

Solving equation (1) and equation (2) we obtained $m$ and $c$ which we was used to convert the values of the new experiment to the referred experiment. These converted predicted values were then compared with the experimental observations.

Moreover, to make the model useful in terms of evaluating biological formulations for obesity and diabetes, we defined reference ranges for the body parameters distinguishing normal mice from obese or diabetic mice. We divided the mice into 3 groups depending on body parameter value. In our reference experiment, the body weight of the ND mice was 27.5 gram and the body weight of the HFHSD mice was 38 gram. So, the first group consisted of mice considered as normal body weight ranges between 27.5 gram to 30.125 gram (25\% away from ND and $75 \%$ from HFHSD). Second group consisted of mice with body weight between 30.125 
a

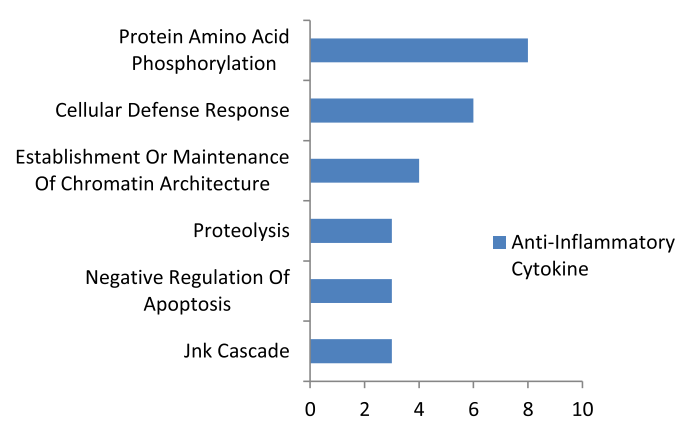

C

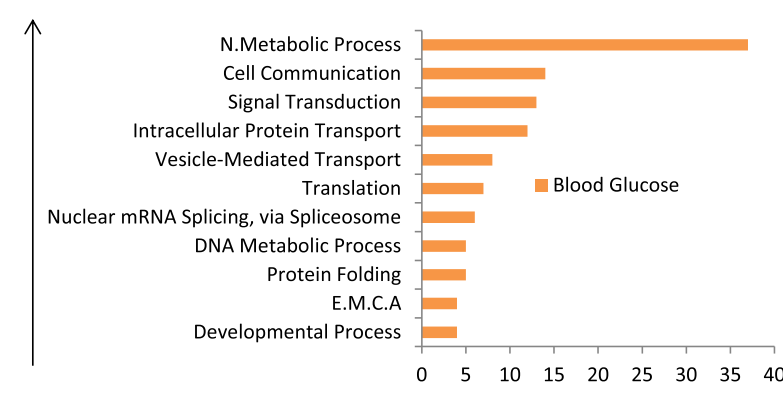

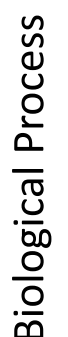

e

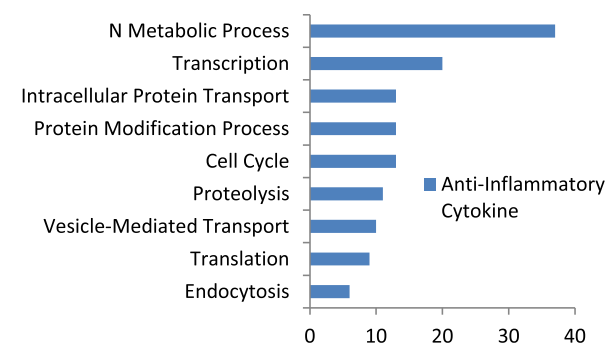

g

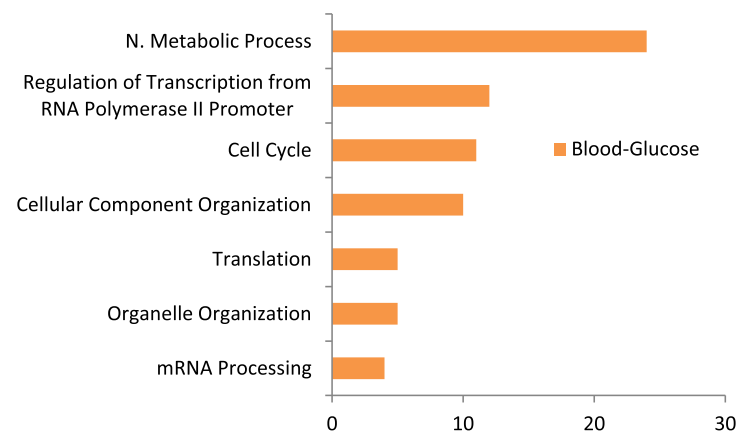

b

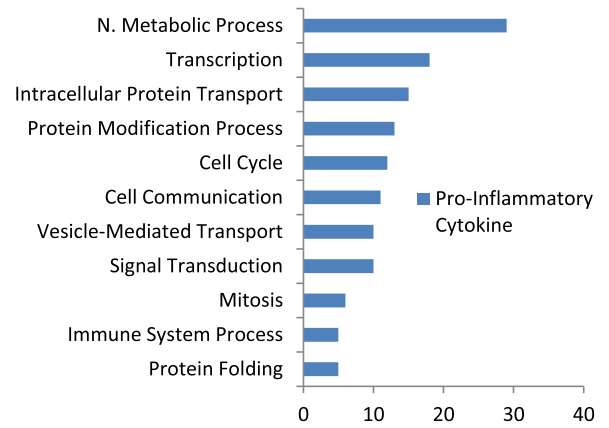

d
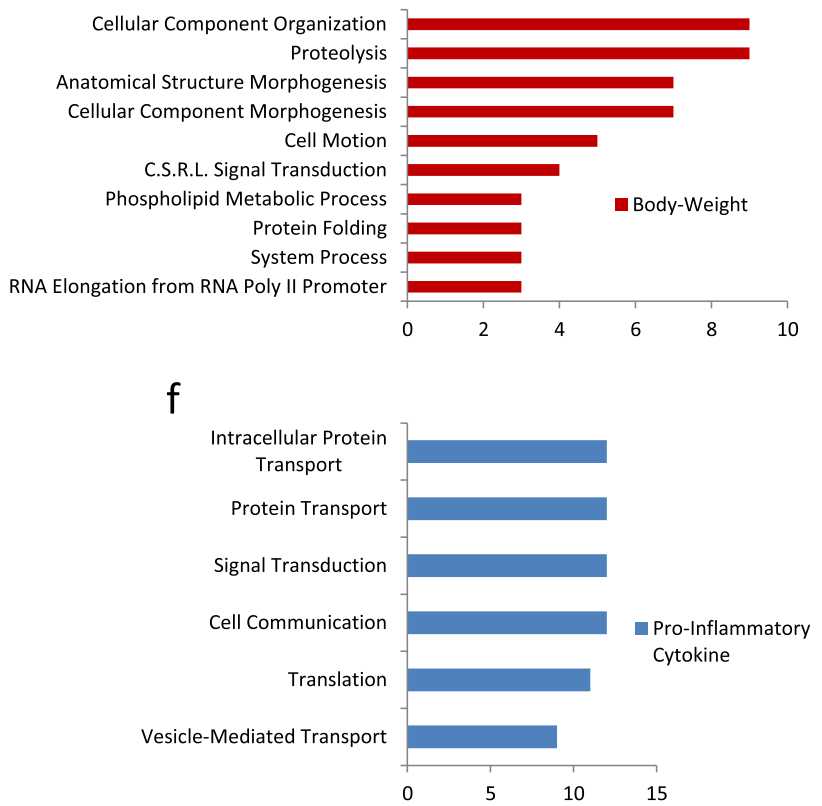

h

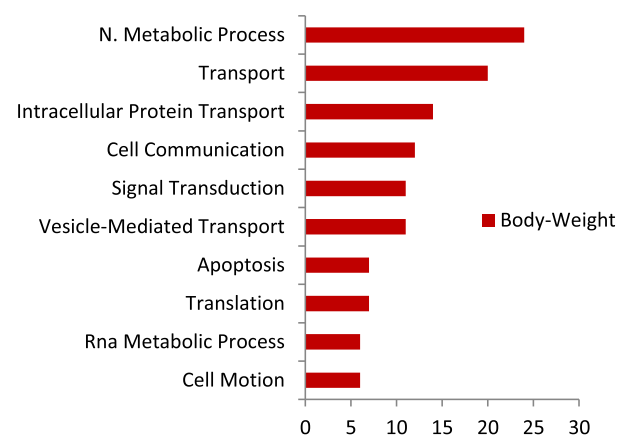

\section{Number of Proteins}

Figure 4 The biological classification for the selected genes used in the models. (a)-(d) The genes selected from the models for the adipose tissue (anti and pro-inflammatory cytokines, blood glucose and body weight). (e) - (h) the genes selected from the models for the skeletal tissue (anti and pro-inflammatory cytokines, blood glucose and body weight). Here, the abbreviations means: N. Metabolic process- Nucleobase, Nucleoside, Nucleotide and Nucleic Acid Metabolic Process; C.S.R.L- Cell Surface Receptor Linked; E M C A- establishment or maintenance of chromatin architecture. 


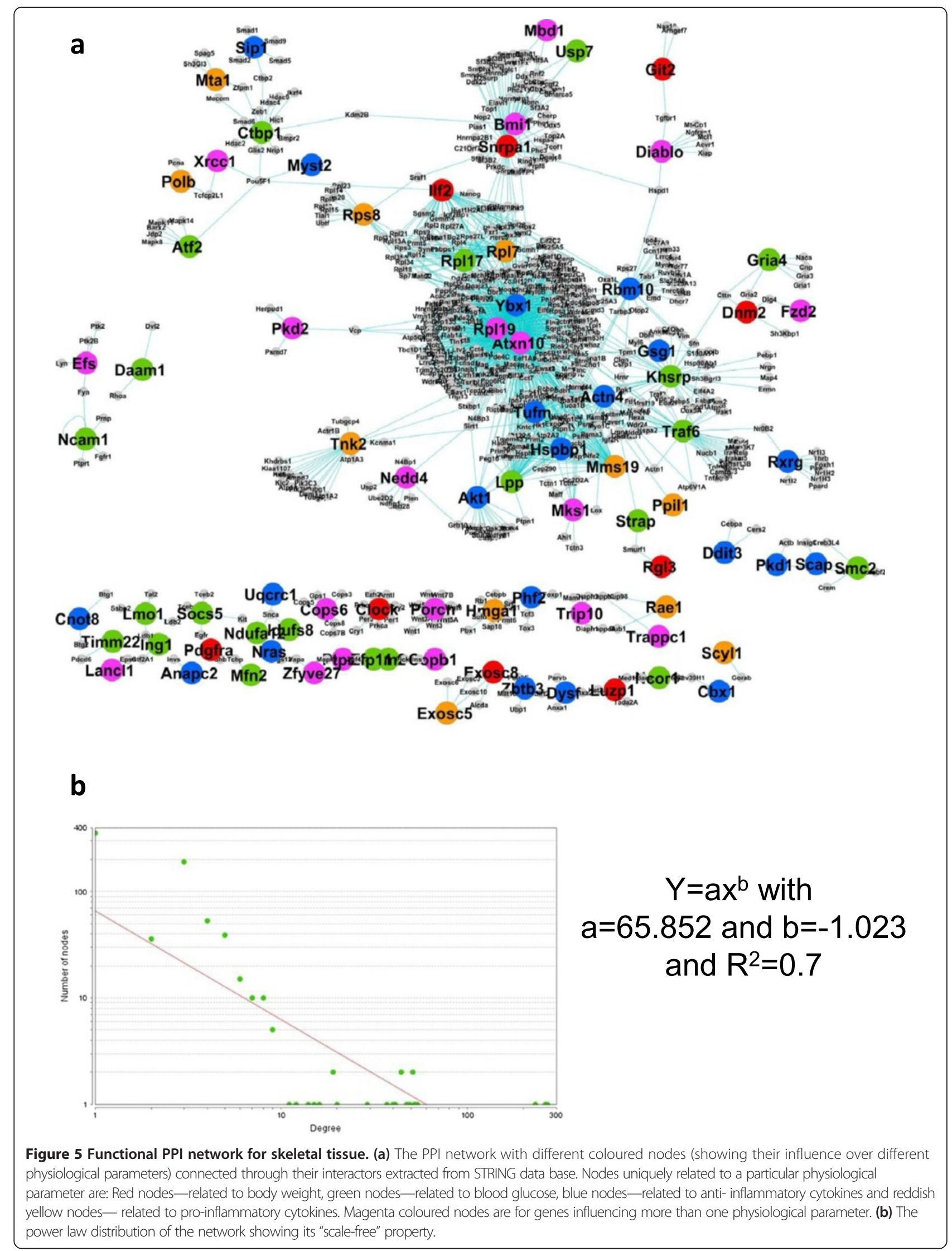




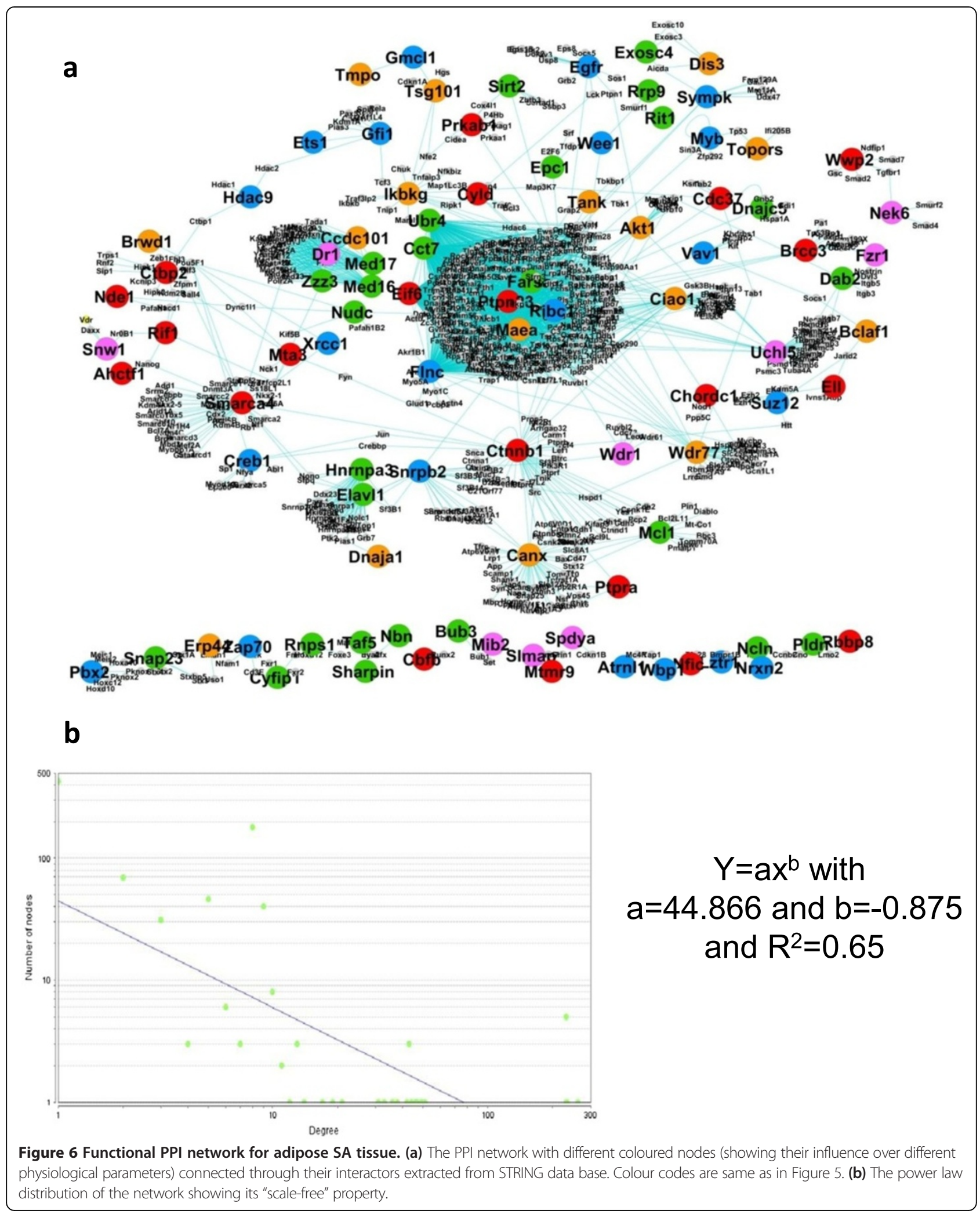

gram to 32.75 gram (50\% from ND and HFHSD). The mice in this group showed sign of possible obesity. For body weight more than 32.75 gram, the mice were said to be obese and we put them in third group. Similarly we proposed ranges for the blood glucose level. In the reference experiment, ND mice had blood glucose level equal to 
Table 7 The parameters related with node connectivity for the sub-networks extracted from the skeletal network given in Figure 5(a)

\begin{tabular}{|c|c|c|c|c|c|c|}
\hline Biological sub-network & $\begin{array}{l}\text { Number of } \\
\text { nodes }\end{array}$ & $\begin{array}{l}\text { Clustering } \\
\text { coefficient }\end{array}$ & $\begin{array}{l}\text { Network } \\
\text { centralization }\end{array}$ & $\begin{array}{l}\text { Avg. number of } \\
\text { neighbours }\end{array}$ & $\begin{array}{l}\text { Network } \\
\text { density }\end{array}$ & $\begin{array}{l}\text { Network } \\
\text { heterogeneity }\end{array}$ \\
\hline $\begin{array}{l}\text { Signal transduction, cell communication } \\
\text { and cell motion }\end{array}$ & 166 & 0.28 & 0.316 & 4.46 & 0.062 & 2.083 \\
\hline Translation and N. Metabolic processes & 526 & 0.516 & 0.507 & 5.038 & 0.05 & 3.967 \\
\hline Apoptosis & 115 & 0.39 & 0.443 & 4.4 & 0.04 & 2.081 \\
\hline
\end{tabular}

$141 \mathrm{mg} / \mathrm{dl}$ and HFHSD was equal to $170 \mathrm{mg} / \mathrm{dl}$. If the glucose level lies between $141 \mathrm{mg} / \mathrm{dl}$ and $148.25 \mathrm{mg} / \mathrm{dl}$, we referred it as normal. Second group consisted of mice with slight increase in blood glucose level $(148.25 \mathrm{mg} / \mathrm{dl}$ to $155.5 \mathrm{mg} / \mathrm{dl}$ ). For blood glucose level more than $155.5 \mathrm{mg} / \mathrm{dl}$, the mice were said to be diabetic and we put them in the third group. If the biological formulation works and keeps the body parameters within the normal range then we denote it by ' + '. If the formulation partially works on the body parameters and the values are in the second group (described above), we denote it by ' + /-'. Finally, in spite of exposing to the formulation, if the body parameter shows obese and or diabetic state then we denote it by '-'.

\section{Model predictions on the effectiveness of unknown formulations for obesity and diabetes}

We performed a blind experiment where the goal was to predict outcomes of HFHSD mice treated with three different ethno-botanical formulations of unknown function. These three blind formulations, named as KAL-A, $K A L-B$, and KAL-C, were obtained from the manufacturer of KAL-1 and the data, in terms of the physiological parameters, were generated in a similar manner. Gene-expression data were generated from the skeletal muscle from different groups at weeks 3 and 6 . We also obtained body parameters (body weight and blood glucose level) for later time point. The body weight and blood glucose of ND mice were 28 grams (week 15) and $138 \mathrm{mg} / \mathrm{dl}$ (week 12) respectively, and the body weight and blood glucose of HFHSD mice were 31 grams (week 15) and $158 \mathrm{mg} / \mathrm{dl}$ (week 12), respectively. Thus the conversion parameters ( $m$ and $c$ ) for the body weight and blood glucose level for this new experiment were $(3.5,-70.5)$ and $(1.45,-59.1)$, respectively. We used these two parameters to compare our prediction with the observed results. The model predictions for the new experiment (KAL-A, KAL-B and KAL-C) are given in Table 4. We observed that our predictions regarding the effectiveness of the biological formulations match with the experimental observations, except in case of border line predictions.

To check the robustness of the proposed models, we further tested them with ten more blind formulations (NF_1, NF_2, NF_3, NF_4, NF_5, NF_6, NF_7, NF_8, NF_9 and NF_10). The body weight and blood glucose of ND mice were 29 grams and $140 \mathrm{mg} / \mathrm{dl}$ respectively. The body weight and blood glucose of HFHSD mice were 34.5 grams and $169.5 \mathrm{mg} / \mathrm{dl}$, respectively. Thus the conversion parameters ( $m$ and $c$ ) for the body weight and blood glucose level for this new experiment were $(1.0972,-8.0273)$ and $(1.017,-1.38)$ respectively. The model prediction for the new experiment with ten blind formulations is given in Tables 5 and 6. We observed that most of the predictions were correct except for some border line cases. Thus, the trained model showed a good first approximation on evaluating the effectiveness of the formulations against obesity and diabetes. Although with the failure in some border line cases, implied the need for further training of the model. Nevertheless, we have a model (trained and tested) that can be used as first-line screen to test the activities of formulations (including pharmacological compounds).

\section{Finding relation between biological processes associated} with the signature genes and the body phenotype

The genes present in the proposed models (selected by the VIP score) could possibly regulate or influence the related physiological parameters. To find the functionality associated with these genes we looked for functional enrichment of the data. We analyzed the protein functional clusters using the online tool called PANTHER (Protein Analysis through Evolutionary Relationships; http://www. pantherdb.org) Classification System. PANTHER is a ontology tool where proteins are classified into families and subfamilies of shared function, which are further assigned to specific ontology terms in the two main categories- biological process and molecular function [16].

Here, we have eight set of genes (each set for each model) for skeletal and adipose SA tissue. Each of these sets are related (through model) with one of the parameter- (1) body weight, (2) blood glucose, (3) anti-inflammatory cytokines and (4) pro-inflammatory cytokines. In each group, we identified the key processes that were associated with these proteins, using the Panther HMM algorithm based on homology and trained on known proteins, see Figure 4. To identify these key processes, we first selected the processes based on significant $\mathrm{p}$ values $(<1 \mathrm{E}-01)$ and the resulting list was further screened by selecting only those processes that involved more than 2 proteins. The list of biological 


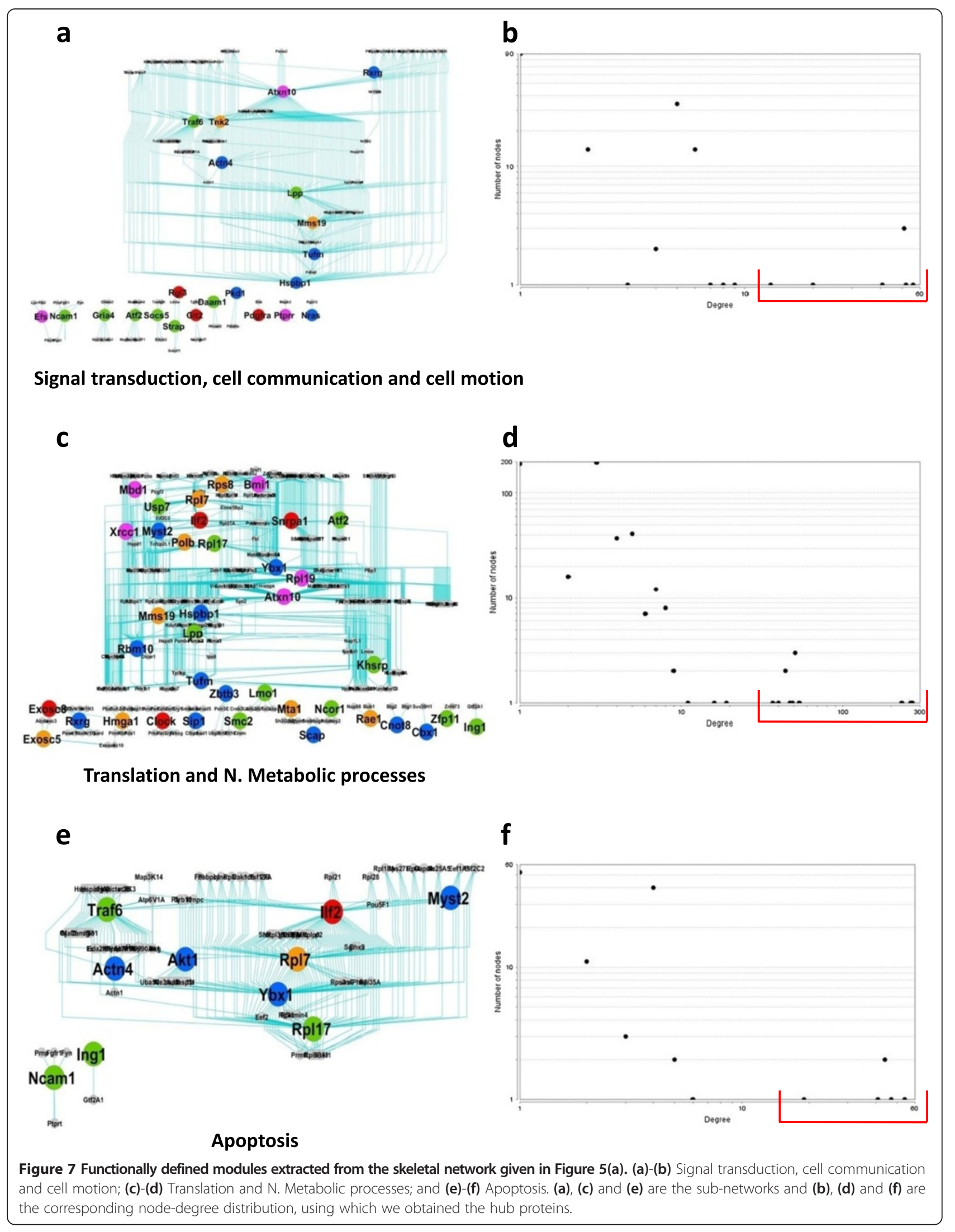


processes obtained for each set of signature gene is given in Additional file 4.

We observed that there were some processes significantly (with $\mathrm{p}$ values $<1 \mathrm{E}-01$ ) present in both tissues (adipose and skeletal) and influence the same physiological parameter. For example, cell communication (with p-value 4.88E-03 in adipose and 1.92E-02 in skeletal), signal transduction (with p-value 4.27E-03 in adipose and 3.35E-02 in skeletal) and vesicle mediated transport (with $\mathrm{p}$-value $2.22 \mathrm{E}-02$ in adipose SA and 3.91E-02 in skeletal) were the key processes involve in both tissues and influence pro-inflammatory cytokine. So, there are lot of initial cell signalling events occurred that influence later time points pro-inflammatory cytokine profiles and this happens in both tissues. We also observed processes like proteolysis and cell motion that were significantly present in both the tissues. Former related to anti-inflammatory cytokines and later influences body weight. For blood glucose we observed translation and nucleobase, nucleoside, nucleotide and nucleic acid metabolic process significantly present in both the tissues.

There was no process commonly involved in all physiological changes for both the tissues, but there were processes uniquely present in each tissue and were involved in a particular physiological change. For example, genes involved in phospholipid metabolic process (9.38E-02) were present in adipose tissue influencing the body weight. This process was involved in the formation of lipid bilayers. Two more processes significantly present in adipose tissue were cellular defence response $(9.58 \mathrm{E}-03)$ and regulation of apoptosis (9.18E-02) and they influenced anti-inflammatory cytokine. We also observed immune response (5.83E-02) in adipose tissue which influences the pro-inflammatory cytokine profiles. In skeletal tissues the key process includes transport (3.21E-02) like intra cellular protein transport and apoptosis (8.07E-02).

\section{Extracting biological network from the signature genes and identification of hub proteins}

We obtained relations between different biological processes and body parameters like body weights, blood glucose levels and cytokine profiles. These processes were obtained from the genes present in the early time point and the body parameters were taken from later time point. This kind of linkage can trace disease development and progression, but for that we need to understand how the perturbations in a protein affect other proteins and how these changes are reflected on the body parameter. For this, we need to construct the protein-protein interaction (PPI) functional network. We used STRING (Search Tool for the retrieval of Interacting genes/ proteins) database, which detect physical and functional associations of the proteins and shows connection between two proteins if they are co-regulated, coexpressed or present in the same protein complex. We downloaded protein-protein interaction from STRING data set and used only those interactions that were obtained directly from experiment. (http://string-db.org/).

We built two PPI networks for the two tissues- skeletal and adipose, by combining the signature genes from all the models (for each tissue). The nodes (present in our list) were represented with different colours and were connected through their interactors extracted from STRING database, see Figures 5(a) and 6(a). In our constructed network we go for different statistical analysis. The first one is the degree-node distribution. The degree distribution is an important statistical property to measure the global structure of large networks [17]. The degree distribution, $P(k)$, describes the probability that a node has degree $k$. A scale-free networks (important property relevant to PPI network [14]) have a power-law degree distribution $P(k)$ $c k^{-\gamma}$, where $\gamma$ is a positive number [17-19]. Our network also showed power law distribution (see Figures 5(b)-6(b)) and hence it possesses "scale free" property.

In both the networks we obtained different enriched sub-networks based on the functional classification with low p-value $\left(<10^{-1}\right)$ obtained using PANTHER. To test the statistical significance of the sub-networks in terms of connectivity, we calculated the parameters like network centralization, network density and network heterogeneity for each of the proposed sub networks. These parameters are related with node connectivity, for example, centralization is an index of the connectivity distribution and network heterogeneity are based on the variance of the connectivity [20]. Moreover in each of these sub-networks (or functional modules) we identified some hub proteins. Here we focused on intra-modular hub proteins which has high clustering coefficient [21].

\section{Functional modules in skeletal tissue}

There were mainly three functionally sub-networks observed in this network. The statistics for each sub-network is given in Table 7. First one was "Signal transduction, cell communication and cell motion" which contains proteins that play a central role in signalling pathway (see Figure 7 (a)). From the node-degree distribution, we obtained the average neighbourhood for each node and took eight nodes (top 5\%, see Figure 7(b)) as hub-nodes, see Table 8. The second sub-network was "Translation and nucleobase, nucleoside, nucleotide and nucleic acid metabolic processes" containing proteins that play a central role in metabolic pathway (see Figure $7(\mathrm{c})$ ). From the node-degree distribution, we obtained ten nodes (top $2 \%$, see Figure $7(\mathrm{~d})$ ) as hub-nodes, see Table 8 . The third sub-network plays a central role in apoptosis (see Figure $7(\mathrm{e})$ ) and we obtained six nodes (top 5\%, see Figure 7(f)) as hub-nodes, see Table 8.

\section{Functional modules in adipose tissue}

Here also three functionally sub-networks were observed and the statistics for each sub-network is given in Table 9. 
Table 8 The list of hub proteins obtained in different modules in the skeletal network given in Figure 5(a)

\begin{tabular}{|c|c|c|c|}
\hline Biological sub-network & Number of hub nodes & Name of the proteins & Number of nodes connected with \\
\hline \multirow[t]{8}{*}{ Signal transduction, cell communication and cell motion } & \multirow[t]{8}{*}{8} & Atxn10 & 56 \\
\hline & & Lpp & 52 \\
\hline & & Mms19 & 19 \\
\hline & & Tufm & 51 \\
\hline & & Hspbp1 & 51 \\
\hline & & Traf6 & 41 \\
\hline & & Tnk2 & 20 \\
\hline & & Actn4 & 13 \\
\hline \multirow[t]{10}{*}{ Translation and N. metabolic processes } & \multirow[t]{10}{*}{10} & Ybx1 & 270 \\
\hline & & Atxn10 & 263 \\
\hline & & Rpl19 & 231 \\
\hline & & Mms19 & 54 \\
\hline & & $\| f 2$ & 47 \\
\hline & & Snrpa1 & 49 \\
\hline & & Rpl17 & 44 \\
\hline & & Rp17 & 44 \\
\hline & & Lpp & 51 \\
\hline & & Hspbp1 & 51 \\
\hline \multirow[t]{6}{*}{ Apoptosis } & \multirow[t]{6}{*}{6} & Traf6 & 41 \\
\hline & & $\| f 2 d$ & 47 \\
\hline & & Rp17 & 44 \\
\hline & & Ybx1 & 54 \\
\hline & & Rpl17 & 44 \\
\hline & & Akt1 & 19 \\
\hline
\end{tabular}

First one was "Signal transduction, cell communication and cell motion" which contained proteins from signalling pathway (see Figure $8(\mathrm{a})$ ). From the node-degree distribution, we obtained five nodes (2\%, see Figure $8(\mathrm{~b})$ ) as hub-nodes, see Table 10. The second sub-network was "Translation, N Metabolic Process, Phospholipid metabolic Process" that play important part in different metabolic process (see Figure $8(\mathrm{c})$ ). Here we obtained eight nodes (top 2\%, Figure 8 (d)) as hub-nodes, see Table 10. The third sub-network consisted of proteins that were part of immune response pathway (see Figure 8(e)). We obtained three nodes (top 3\%, see Figure 8(f)) as hub-nodes, see Table 10.

\section{Discussion}

Present study was devoted in finding gene signatures for obesity and diabetes systemic inflammation. Using the partial least square discriminant analysis (PLS-DA) method, we identified early gene/molecular signatures that predicted future values of physiological parameters like body weight, blood glucose levels and cytokine profiles. The models worked better for Skeletal \& Adipose SA tissues in predicting body weight and blood glucose (two important physiological parameters for obesity and diabetes). To test the effectiveness of the biological formulations against obesity and diabetes, we set cut-off values for the body

Table 9 The parameters related with node connectivity for the sub-networks extracted from the adipose SA network given in Figure 6(a)

\begin{tabular}{lllllll}
\hline Biological sub-network & $\begin{array}{l}\text { Number of } \\
\text { nodes }\end{array}$ & $\begin{array}{l}\text { Clustering } \\
\text { coefficient }\end{array}$ & $\begin{array}{l}\text { Network } \\
\text { centralization }\end{array}$ & $\begin{array}{l}\text { Avg. Number of } \\
\text { neighbours }\end{array}$ & $\begin{array}{l}\text { Network } \\
\text { density }\end{array}$ & $\begin{array}{l}\text { Network } \\
\text { heterogeneity }\end{array}$ \\
\hline $\begin{array}{l}\text { Cell communication, signal } \\
\text { transduction, cell motion }\end{array}$ & 386 & 0.583 & 0.676 & 3.176 & 0.008 & 5.608 \\
$\begin{array}{l}\text { Translation, N. Metabolic process, } \\
\text { Phospho-lipid Metabolic process }\end{array}$ & 459 & 0.613 & 0.499 & 3.542 & 0.008 & 4.448 \\
\begin{tabular}{l} 
Immune response \\
\hline
\end{tabular} & 90 & 0.023 & 0.504 & 2.111 & 0.024 & 2.398 \\
\hline
\end{tabular}


a

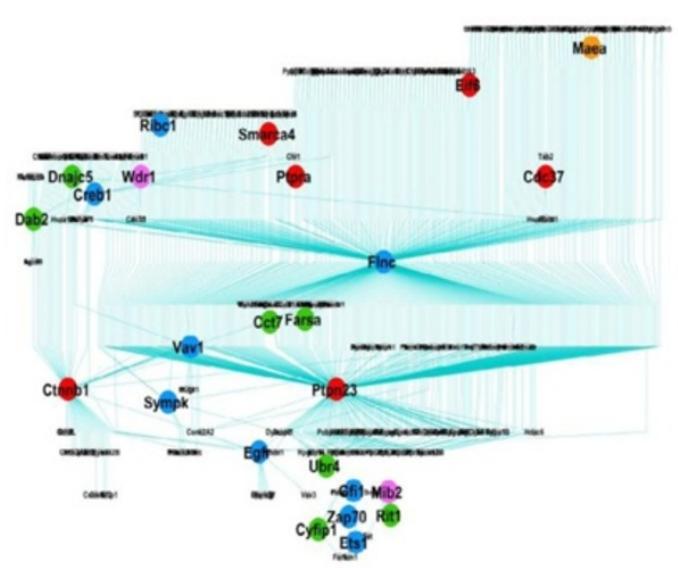

b

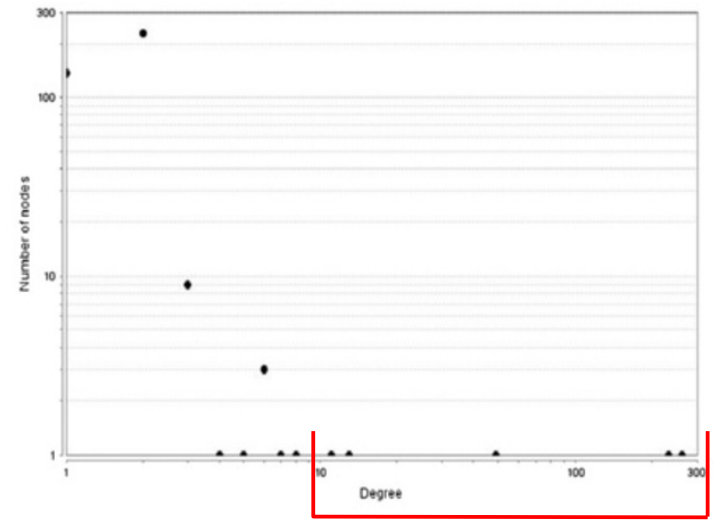

Signal transduction, cell communication and cell motion

C

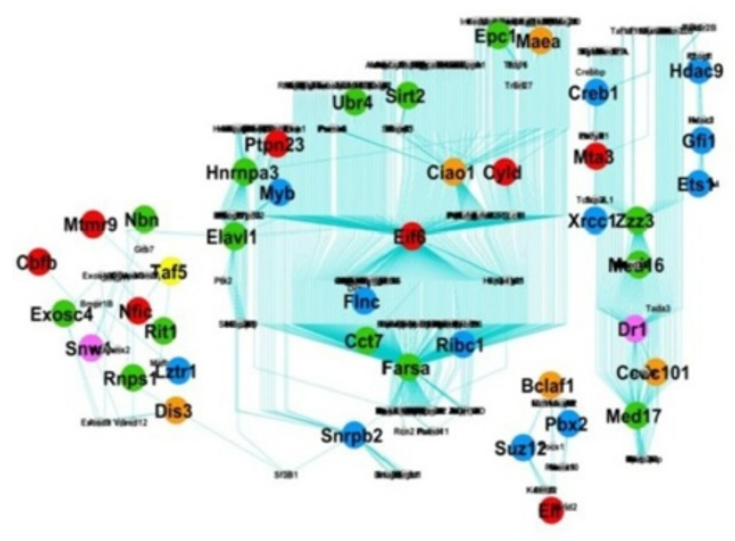

d

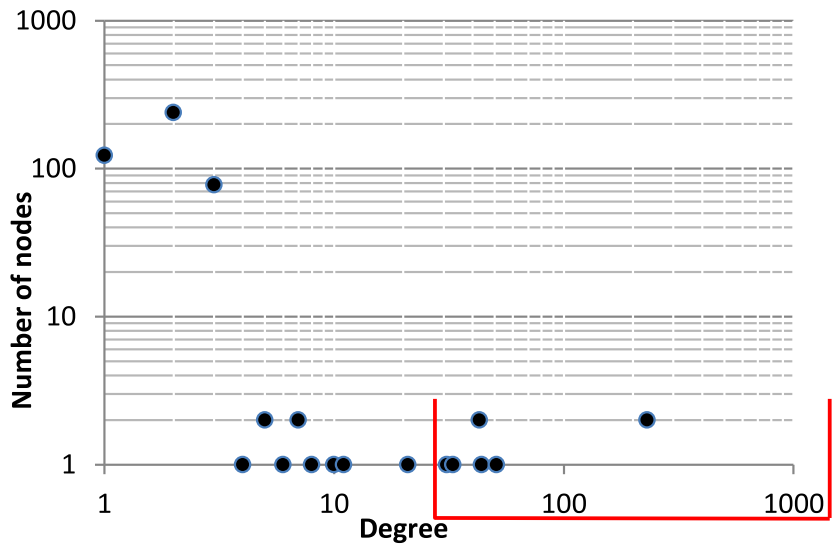

Translation, Phospholipid and N Metabolic Process

f

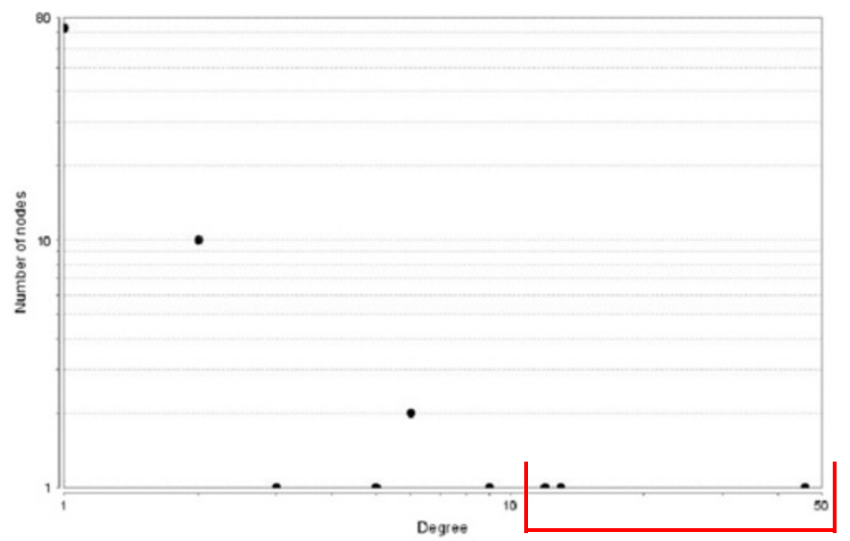

e

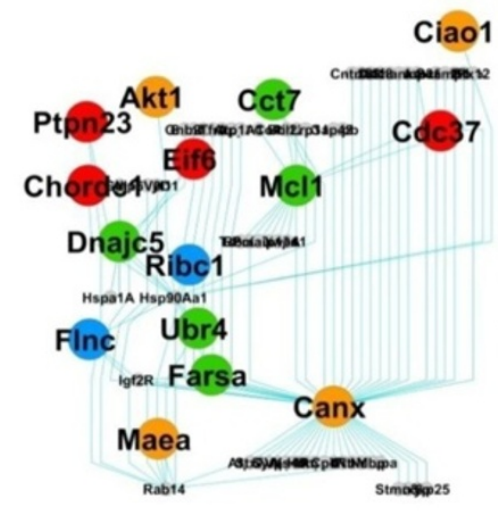

\section{Cellular defense and immune response}

\section{Gmcl1}

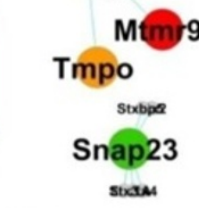

vav1

Plocin
Socsi

Figure 8 Functionally defined modules extracted from the adipose SA network given in Figure 6(a). (a)-(b) Signal transduction, cell communication and cell motion; (c)-(d) Translation, N. Metabolic processes and Phospho-lipid Metabolic Process; and (e)-(f) Immune response. (a), (c) and (e) are the sub-networks and (b), (d) and (f) are the corresponding node-degree distribution, using which we obtained the hub proteins. 
Table 10 The list of hub proteins obtained in different modules in adipose SA network given in Figure 6(a)

\begin{tabular}{|c|c|c|c|}
\hline Biological sub-network & Number of hub nodes & Name of the proteins & $\begin{array}{l}\text { Number of nodes } \\
\text { connected with }\end{array}$ \\
\hline \multirow[t]{5}{*}{ Cell communication, signal transduction, cell motion } & \multirow[t]{5}{*}{5} & Flnc & 262 \\
\hline & & Ptpn23 & 232 \\
\hline & & Ctnnb1 & 47 \\
\hline & & Egfr & 13 \\
\hline & & Creb1 & 11 \\
\hline \multirow{8}{*}{ Translation, N. Metabolic process, Phospho-lipid metabolic process } & \multirow[t]{8}{*}{8} & Eif6 & 231 \\
\hline & & Farsa & 231 \\
\hline & & Ciaol & 51 \\
\hline & & Zzz3 & 44 \\
\hline & & Dr1 & 43 \\
\hline & & Med17 & 43 \\
\hline & & Elavl1 & 33 \\
\hline & & Hnrnpa3 & 31 \\
\hline \multirow[t]{3}{*}{ Immune response } & \multirow[t]{3}{*}{3} & Canx & 46 \\
\hline & & Hsp90Aa1 & 13 \\
\hline & & Mcl1 & 12 \\
\hline
\end{tabular}

weights and blood glucose levels. It was observed that the models, with these cut offs, work well in evaluating the formulations, except in some border cases for which the model needed further training. Thus, we have models that predict future body weight and blood glucose level from early gene expression values, which could be a good starting platform for screening experiment.

We also studied the functionality of the obtained signature genes for each model. We observed that some of the biological processes were common in both the tissues and influenced more than one physiological parameter. There were biological processes uniquely present in a tissue and were associated with a particular physiological parameter. After identifying the significant biological processes ( $\mathrm{p}$-value $<1 \mathrm{E}-01$ ) for both skeletal and adipose SA, we used them to build functional modules for both the tissues (using STRING database). Studying those modules carefully we obtained hub proteins with some of them has the potential to be an early marker for obesity and diabetes.

For skeletal tissues we obtained 15 unique hub proteins from different modules, influencing different future physiological parameters and for adipose tissue we obtained 16 unique hub proteins, see Additional file 5 (proteins with their functional modules and the physiological parameters).

We observed heat shock proteins Hspbp1 in skeletal tissue (signaling and metabolic module) influencing future anti-inflammatory cytokine profiles. Heat shock proteins (HSPs) function at the cellular level to protect cells against many chronically and acutely stressful conditions [22]. Thus response to early stress due to HFHSD was observed in the mice. Another key protein identified in apoptosis pathway and influence future blood glucose level was Akt1. We know that Akt1 phosphorylation is essential for insulin signaling in skeletal muscle [23]. Our study identified Akt1 as a key signature gene in skeletal tissue for predicting future blood glucose level. Another key signature gene in skeletal tissue was Ybx1 which predicts future antiinflammatory cytokine profiles. This is an interesting result because Ybx1 is an important molecule associated with inflammatory stress [24] and here its early expression in the skeletal tissue was used to predict the future outcome in terms of inflammation. We have also identified some key ribosomal proteins (Rpl17, Rpl19, and Rp17) as signature molecules for predicting future inflammatory stress.

In adipose SA we found key proteins from signaling pathway, metabolic pathway and immune response. Immune response and metabolic regulation are highly integrated function and any kind of dysfunction may lead to a cluster of chronic metabolic disorders, particularly obesity, type-II diabetes and cardiovascular disease [25]. In immune response module we found a highly connected molecule Calnexin which is an important molecule found in obesity [26]. We identified a key signature protein Flnc (highly connected in the signaling module) associated with future inflammation stress. This protein is known to associate with obesity and diabetes [27]. Ctnnb1 is another important protein identified in the signaling module, known as an important players in Wnt and p53 signalling pathways, which would provide a putative link between Type-II diabetes and certain types of cancer [28]. This identified key signature is observed to influence the future body weight. 


\section{Conclusion}

We proposed sets of gene/molecular signatures for predicting different physiological parameters associated with obesity and diabetes. This could be used as a first step in evaluating effectiveness of the formulations against obesity and diabetes. Our analysis revealed that some of the identified key signature genes have the potential to become early biomarker for obesity and diabetes, admittedly however, it necessitates further validation.

\section{Additional files}

\section{Additional file 1: Master Gene List. \\ Additional file 2: Appendix for variable importance. \\ Additional file 3: Gene list as input in the models. \\ Additional file 4: Biological process/pathways. \\ Additional file 5: Key proteins and their functional modules.}

\section{Competing interests}

The authors declare that they have no competing interests.

\section{Authors' contributions}

NS performed the PLSR analysis and network analysis. SS, PT and KT isolated tissues and extracted RNA for micro-array. SKN performed the initial data analysis and PLSR analysis. DK designed the PLSR analysis. KVSR conceived and managed the overall project. SC designed the initial data analysis and PLSR analysis, performed the network analysis, interpreted the results and wrote the manuscript. All authors read and approved the final manuscript.

\section{Acknowledgement}

This article is based on studies designed to assess the safety and potentia physiologic effects of selected natural constituents of common Ayurveda mixtures. Studies were partially funded by PepsiCo, Inc. However the views expressed in this article are those of the author(s) and do not necessarily reflect the position or policy of PepsiCo, Inc.

Received: 18 July 2012 Accepted: 18 August 2014

Published: 30 August 2014

\section{References}

1. Alwan A: The World Health Report. http://www.who.int/nmh/publications/ ncd report2010/en/.

2. Hill JO, Peters JC, Catenacci VA, Wyatt HR: International strategies to address obesity. Obes Rev 2008, 9(Suppl 1):41-47.

3. Haslam DW, James WPT: Obesity. Lancet 2005, 366(9492):1197-1209.

4. Kopelman PG: Obesity as a medical problem. Nature 2000, 404(6778):635-643.

5. Shao W, Yu Z, Chiang Y, Yang Y, Chai T, Foltz W, Lu H, Fantus IG, Jin T: Curcumin prevents high fat diet induced insulin resistance and obesity via attenuating lipogenesis in liver and inflammatory pathway in adipocytes. PLoS One 2012, 7(1):e28784.

6. Tikoo K, Misra S, Rao KV, Tripathi P, Sharma S: Immunomodulatory Role of an Ayurvedic Formulation on Imbalanced Immunometabolics during Inflammatory Responses of Obesity and Prediabetic Disease. Evid base Compl Alternative Med 2013, 2013:795072.

7. Perez-Enciso M, Tenenhaus M: Prediction of clinical outcome with microarray data: a partial least squares discriminant analysis (PLS-DA) approach. Hum Genet 2003, 112(5-6):581-592.

8. Lin S, Thomas TC, Storlien LH, Huang XF: Development of high fat dietinduced obesity and leptin resistance in C57BI/6 J mice. Int J Obes Relat Metab Disord 2000, 24(5):639-646.

9. Petro AE, Cotter J, Cooper DA, Peters JC, Surwit SJ, Surwit RS: Fat, carbohydrate, and calories in the development of diabetes and obesity in the C57BL/6 J mouse. Metabolism 2004, 53(4):454-457.

10. Surwit RS, Feinglos MN, Rodin J, Sutherland A, Petro AE, Opara EC, Kuhn CM, Rebuffe-Scrive M: Differential effects of fat and sucrose on the development of obesity and diabetes in C57BL/6 J and A/J mice. Metabolism 1995, 44(5):645-651.

11. Staehr $\mathrm{P}$, Hother-Nielsen $\mathrm{O}$, Beck-Nielsen $\mathrm{H}$ : The role of the liver in type 2 diabetes. Rev Endocr Metab Disord 2004, 5(2):105-110.

12. Juge-Aubry CE, Henrichot E, Meier CA: Adipose tissue: a regulator of inflammation. Best Pract Res Clin Endocrinol Metab 2005, 19(4):547-566.

13. Lin Y, Sun Z: Current views on type 2 diabetes. J Endocrinol 2010, 204(1):1-11.

14. Barabasi AL, Albert R: Emergence of scaling in random networks. Science 1999, 286(5439):509-512.

15. Korhonen O, Matero S, Poso A, Ketolainen J: Partial least square projections to latent structures analysis (PLS) in evaluating and predicting drug release from starch acetate matrix tablets. J Pharm Sci 2005, 94(12):2716-2730.

16. Mi H, Thomas P: PANTHER pathway: an ontology-based pathway database coupled with data analysis tools. Methods Mol Biol 2009, 563:123-140.

17. Przulj N, Corneil DG, Jurisica I: Modeling interactome: scale-free or geometric? Bioinformatics 2004, 20(18):3508-3515.

18. Barabasi A-L, Oltvai ZN: Network biology: understanding the cell's functional organization. Nat Rev Genet 2004, 5(2):101-113.

19. Yook SH, Oltvai ZN, Barabasi AL: Functional and topological characterization of protein interaction networks. Proteomics 2004, 4(4):928-942.

20. Dong J, Horvath S: Understanding network concepts in modules. BMC Syst Biol 2007, 1:24

21. Liang $H_{1} \mathrm{Li}$ WH: MicroRNA regulation of human protein protein interaction network. RNA 2007, 13(9):1402-1408

22. Chung J, Nguyen AK, Henstridge DC, Holmes AG, Chan MH, Mesa JL, Lancaster Gl, Southgate RJ, Bruce CR, Duffy SJ, Horvath I, Mestril R, Watt MJ, Hooper PL, Kingwell BA, Vigh L, Hevener A, Febbraio MA: HSP72 protects against obesity-induced insulin resistance. Proc Natl Acad Sci U S A 2008, 105(5):1739-1744.

23. Lee $J H$, Ragolia L: AKT phosphorylation is essential for insulin-induced relaxation of rat vascular smooth muscle cells. Am J Physiol Cell Physiol 2006, 291(6):C1355-C1365.

24. Shelton RC, Claiborne J, Sidoryk-Wegrzynowicz M, Reddy R, Aschner M, Lewis DA, Mirnics K: Altered expression of genes involved in inflammation and apoptosis in frontal cortex in major depression. Mol Psychiatry 2011 16(7):751-762.

25. Hotamisligil GS: Inflammation and metabolic disorders. Nature 2006, 444(7121):860-867.

26. van Noort $V$, Snel B, Huynen MA: The yeast coexpression network has a small-world, scale-free architecture and can be explained by a simple model. EMBO Rep 2004, 5(3):280-284.

27. Kaput J, Klein KG, Reyes EJ, Kibbe WA, Cooney CA, Jovanovic B, Visek WJ, Wolff GL: Identification of genes contributing to the obese yellow Avy phenotype: caloric restriction, genotype, diet x genotype interactions. Physiol Genomics 2004, 18(3):316-324.

28. Jesmin J, Rashid MS, Jamil H, Hontecillas R, Bassaganya-Riera J: Gene regulatory network reveals oxidative stress as the underlying molecular mechanism of type 2 diabetes and hypertension. BMC Med Genomics 2010, 3(1):45.

\section{doi:10.1186/s12918-014-0104-4}

Cite this article as: Sinha et al:: Molecular signatures for obesity and associated disorders identified through partial least square regression models. BMC Systems Biology 2014 8:104. 